Revista Educação e Políticas em Debate - v. 7, n. 1, p. 95 - 112 - jan./abr. 2018 - ISSN 2238-8346

\title{
Educação do campo: o entrelaçar de saberes no ensino de Ciências e de Matemática
}

\author{
Rural education: the integrated knowledges in sciences and mathematics teaching
}
L'éducation en milieu rural: la formation des connaissances en l'enseignement des sciences et mathématiques

Patrícia Ferreira dos Santos ${ }^{1}$

Universidade Federal do Triângulo Mineiro

Diego dos Santos Leon ${ }^{2}$

Universidade Federal do Triângulo Mineiro

Danilo Seithi Kato ${ }^{3}$

Universidade Federal do Triângulo Mineiro

Daniel Fernando Bovolenta Ovigli ${ }^{4}$

Universidade Federal do Triângulo Mineiro

Resumo: $\mathrm{O}$ trabalho em tela, de caráter qualitativo, insere-se no âmbito da educação do campo e foi desenvolvido no assentamento Santo Inácio Ranchinho, localizado no município de Campo Florido - MG. Teve como objetivo conhecer as concepções dos sujeitos do campo sobre educação, ensino e escola. Trata-se de uma pesquisa de campo durante a qual foram realizadas visitas ao assentamento, bem como duas entrevistas semiestruturadas com moradores. Como produto gerado a partir do mapeamento inicial, é proposta uma intervenção no processo de ensino-aprendizagem por meio da construção de uma horta agroecológica. Os dados revelaram uma luta destes sujeitos por uma educação no campo que reconheça e valorize sua cultura e seus saberes.

Palavras-chave: Educação do Campo. Ensino de Ciências e de Matemática. Agroecologia.

Abstract: This paper, a qualitative research, is inserted in the field of rural education and was developed at Santo Inácio Ranchinho settlement, located in Campo Florido/MG city. It aimed to know the concepts about rural education, teaching and school, in the vision of two people that lives there. The immersion was established from the visit to the settlement and the realization of semi structured interviews. As a product generated from the initial mapping, an

\footnotetext{
${ }^{1}$ Mestra em Educação pelo Programa de Pós-Graduação em Educação da Universidade Federal do Triângulo Mineiro (PPGE/UFTM).E-mail.patricia_26_santos@hotmail.com

${ }^{2}$ Mestre em Educação pelo Programa de Pós-Graduação em Educação da Universidade Federal do Triângulo Mineiro (PPGE/UFTM).E-mail.dileon2@gmail.com

${ }_{3}^{3}$ Doutor em Educação Escolar (UNESP). Professor do Departamento de Educação em Ciências da Natureza, Matemática e Tecnologias (DECMT), no Curso de Licenciatura em Educação do Campo. E-mail. danilo.kato@uftm.edu.br

${ }^{4}$ Doutor em Educação para a Ciência (UNESP/Bauru). Professor do Departamento de Educação em Ciências da Natureza, Matemática e Tecnologias (DECMT), vinculado ao Instituto de Ciências Exatas, Naturais e Educação (ICENE). E-mail. daniel.ovigli@uftm.edu.br.
} 
intervention in the teaching-learning process is proposed through the construction of an agroecological garden. The data revealed a struggle of these people for rural education that recognizes their values, culture and knowledge.

Keywords: Rural Education. Science and Mathematics Teaching. Agroecology.

Résumé: Le travail sur toile, de nature qualitative, fait partie de l'éducation en milieu rural et a été développé dans la colonie de Santo Inácio Ranchinho, située dans la municipalité de Campo Florido - MG. Il visait à connaître les concepts des sujets du domaine de l'éducation, de l'enseignement et de l'école. L'immersion dans le domaine a été établie à partir de la visite à la colonie et de la réalisation d'entrevues semi-structurées. En tant que produit issu de la cartographie initiale, une intervention dans le processus d'enseignement-apprentissage est proposée à travers la construction d'un jardin agroécologique. Les données ont révélé une lutte de ces sujets pour une l'éducation en milieu rural qui reconnaît et valorise leur culture et leurs connaissances. D'eux, une proposition didactique pour l'enseignement des sciences et des mathématiques basée sur le concept de l'agroécologie a été présentée.

Mots-clés: L'éducation en Milieu Rural. Enseignement des Sciences et des Mathématiques. Agroécologie.

Recebido em: 23 de setembro de 2018 Aceito em: 31 de dezembro de 2018

\section{O contexto de discussão sobre a Educação do Campo}

Antes de iniciarmos nossas discussões em torno do movimento da Educação do Campo buscamos, primeiramente, compreender o contex to do qual falamos e quais são os sujeitos nele envolvidos. Para tanto, nos atentamos em realizar uma leitura densa em torno da cultura deste movimento (GEERTZ, 2008; CALDART, 2009), a fim de compreender quais são os aspectos que configuraram este espaço de formação.

Além disso, ao adentrarmos a um espaço desconhecido e permeado por estereótipos e preconceitos, faz-se necessário rever determinados pré-conceitos e concepções, para enfim fazer emergir um novo conhecimento. Dessa forma,

para se conceber uma educação a partir do campo e para o campo, é necessário mobilizar e colocar em xeque ideias e conceitos há muito estabelecidos pelo senso comum. Mais do que isso, é preciso desconstruir paradigmas, preconceitos e injustiças, a fim de reverter as desigualdades educacionais, historicamente construídas, entre campo e cidade (BRASIL, 2007, p.13).

Para Geertz (2008, p. 10), a cultura pode ser entendida como um contexto e os fenômenos que ocorrem em seu interior podem ser descritos "de forma inteligível - isto é, 
descritos com densidade". Assim, de acordo com ele, compreender a cultura do outro é tornála acessível para os outros:

[...] compreender a cultura de um povo expõe sua normalidade sem reduzir sua particularidade. (Quanto mais eu tento seguir o que fazem os marroquinos, mais lógicos e singulares eles me parecem.) Isso os torna acessíveis: colocá-los no quadro de suas próprias banalidades dissolve sua opacidade (GEERTZ, 2008, p. 10).

Da mesma forma que Geertz (2008), Rocha e Eckert (2008, p. 3) informam que a observação, o conhecer o outro traz como fundamento uma "relação dialética que implica em uma sistemática reciprocidade cognitiva entre o(a) pesquisador(a) e os sujeitos pesquisados”. A Educação do Campo surgiu em meio a movimentos e lutas sociais. Por isso é extremamente importante reconhecer que temos como atores principais deste cenário camponeses que batalham por direitos que lhes têm sido historicamente negados e, assim, vivenciam momentos de tensões e conflitos buscando, além de outros, uma educação que possa lhes garantir uma vida mais justa e de qualidade. São “ $[\ldots .$.$] trabalhadores 'pobres do campo', trabalhadores sem-$ terra, sem trabalho, [...] já dispostos a reagir, a lutar, a se organizar contra 'o estado da coisa', para aos poucos buscar ampliar o olhar para o conjunto dos trabalhadores do campo" (CALDART, 2009, p.41).

Trata-se de sujeitos politizados que estão em processo de “tomada de consciência”. Ou seja, estes sujeitos se reconhecem neste universo e apresentam uma consciência crítica e reflexiva da situação real que vivenciam. Esta conscientização significa o começo da busca de uma posição de luta política, ideológica e social em prol da transformação de si e deste espaço (FREIRE; 1967, 1979).

Em uma perspectiva emancipadora, a Educação do Campo deve ser compreendida a partir de sua totalidade, ou seja, dos movimentos e das tensões que a envolvem, e não restrita a determinadas abordagens de caráter limitado (FREIRE, 1994; CALDART, 2009). Dessa forma, procuramos entender determinados elementos históricos que permeiam a configuração da Educação no Campo.

A educação no Brasil, em geral, sempre foi vista a partir do ponto de vista da cultura letrada, que reflete a ideologia da classe dominante. Determinados grupos, especificamente os mais "pobres”, ficaram às margens das políticas educacionais. A educação do campo é um destes exemplos de exclusão. Na Constituição de 1891, por exemplo, a Educação no Campo sequer 
Revista Educação e Políticas em Debate - v. 7, n. 1, p. 95 - 112 - jan./abr. 2018 - ISSN 2238-8346

foi citada, mesmo o Brasil sendo considerado um país eminentemente agrário (NASCIMENTO, 2009).

Cabe destacar que a escola no campo brasileiro surge tardiamente e não institucionalizada pelo Estado, mantendo uma relação hierárquica com a escola da cidade. Foi a partir da década de 1970 que os movimentos em prol da Educação no Campo voltam a despertar olhares havendo, nesta mesma década, a constituição do Movimento Nacional Articulador por uma Educação no Campo, que defendia a democratização e a reivindicação dos direitos para este segmento social. Esse movimento caracterizou-se como o gérmen do que resultou, anos mais tarde, na previsão de medidas de adequação da escola à vida no campo ratificada na Lei de Diretrizes e Bases da Educação Nacional (LDBEN) (BRASIL, 1996).

No contex to atual, pesquisadores e educadores têm se preocupado com as questões que envolvem a Educação do Campo. No entanto, frente às dimensões do território brasileiro e à desigualdade social, os avanços recentes na Educação do Campo ainda são insuficientes, o que mostra a necessidade de estudos sobre o assunto.

Tendo em vista tais questões, buscamos as vozes de dois sujeitos que vivenciam esta realidade a fim de compreender quais as suas concepções sobre educação, escola e como estas podem ser relacionadas ao ensino de Ciências e de Matemática. A partir destes diálogos, em uma perspectiva intercultural, apresentaremos encaminhamentos para uma proposta didática voltada ao ensino de Ciências e Matemática elaborada em consonância com a perspectiva de uma educação no campo e do campo. Nosso intuito é colaborar com o desenvolvimento de uma Educação do Campo que atenda às necessidades dos sujeitos envolvidos neste contexto.

\section{A Educação do Campo em foco: por uma política de Educação do Campo}

Por uma questão conceitual, Educação no Campo e Educação do Campo possuem significações diferentes. Segundo Caldart (2002) é necessário pensar em uma educação que seja do e no campo e não simplesmente no campo, expressão que remete à transferência da educação que já ocorre na cidade para o ambiente rural. Para a autora (2002, p.18), “No: o povo tem direito a ser educado no lugar onde vive; $D o$ : o povo tem direito a uma educação pensada desde o seu lugar e com a sua participação, vinculada à sua cultura e às suas necessidades humanas e sociais".

É preciso também tomar o campo como um espaço de cultura, rico e diverso, de criação do novo e do criativo, é ao mesmo tempo produto e produtor de cultura. De acordo com 
Munarim (2006), é necessário superar a visão dicotômica entre campo e cidade, que vê o ambiente rural a partir de uma perspectiva de inferioridade ou, ainda, como local de atraso. Ao contrário, o campo é um espaço emancipatório, território para a construção da democracia e da solidariedade, lugar não apenas das lutas pelo direito à terra, mas também pelo direito à educação, à saúde, ao meio ambiente.

Devemos deixar claro que "a Educação do campo toma posição, age, desde uma particularidade e não abandona a perspectiva da universalidade, mas disputa sua inclusão nela” (CALDART, 2009, p.38). O campo não pode ter suas peculiaridades desprezadas, não pode ser reduzido a um parâmetro único, geralmente urbanizador. Dessa maneira, necessita de uma política educacional capaz de reconhecer que a cidade não é superior ao campo.

A Educação do Campo também não pode ser considerada fora de sua identidade, de sua cultura e subculturas. A identidade da escola do campo, por exemplo, não é circunscrita a apenas um espaço geográfico. A identidade da escola do campo é definida a partir dos sujeitos sociais a quem se destina. Além disso, deve estar vinculada a uma cultura que se produz por meio de relações mediadas pelo trabalho, sendo o trabalho entendido como produção material e cultural de existência humana.

Os princípios da Educação do Campo são como as raízes de uma árvore, que tiram a seiva da terra (conhecimentos), que nutrem a escola e fazem com que ela tenha flores e frutos (a "cara" do lugar onde ela está inserida e dos sujeitos sociais a quem se destina). Deste modo, suscita a adequação da escola e do trabalho pedagógico do professor à vida e às necessidades reais dos alunos do campo, reconhecendo e valorizando os alunos como sujeitos ativos, entendendo que a proposta pedagógica praticada na sala de aula deve influenciar diretamente no envolvimento dos alunos, na aprendizagem e na superação de suas dificuldades.

Para que isso aconteça determinadas questões precisam ser discutidas como, por exemplo, o currículo e a formação de professores para atuarem no campo. A reflexão sobre a relação prática-teoria-prática (práxis) é outro indicativo, pois, por meio desta, podemos buscar saídas e alternativas para romper com o modelo de educação elitizada.

Nessa perspectiva, consideramos urgente a elaboração de trabalhos que permeiem as diversas esferas da Educação do Campo. Isto posto, procuramos adentrar à realidade dos sujeitos do campo, convidando-os para um diálogo. Entendemos que estas pessoas trazem consigo experiências e saberes que podem e devem ser considerados para a construção e reconstrução de conhecimentos nas diversas áreas do saber, em nosso caso, no ensino de Ciências e de Matemática. 


\section{Construção do material empírico: uma busca da(s) voz(es) do(s) sujeito(s)}

Diante do contexto da pesquisa, optamos por realizar um trabalho fundamentado na perspectiva qualitativa, referendada por Bogdan e Biklen (1994). Acreditamos que a abordagem qualitativa possui um aspecto mais subjetivo, permitindo uma pesquisa com narrativas mais ricas e subjetivas (TRIVIÑOS, 1987).

Os dados foram levantados por meio de pesquisa de campo e entrevistas semiestruturadas (MARCONI; LAKATOS, 2010) direcionadas a dois sujeitos do campo - um licenciando do curso de Educação do Campo - habilitação em Matemática (João) e o outro, professor de Filosofia (Otávio), ambos moradores do assentamento Santo Inácio Ranchinho, comunidade situada no município de Campo Florido - Minas Gerais. Cabe ressaltar que os nomes dos participantes são fictícios, a fim de que o risco de perda de confidencialidade seja minimizado. As entrevistas foram gravadas em áudio e transcritas de forma literal.

Ademais foi realizada uma visita in loco na comunidade para imersão na realidade estudada. Esta fase pode ser caracterizada como pesquisa de campo, que consistiu na “[ [...] observação dos fatos e fenômenos que ocorreram espontaneamente durante o processo de investigação, representando variáveis relevantes para a análise dos dados” (MARCONI; LAKATOS, 2010, p. 69).

Entendemos que aspectos subjetivos emergem durante o processo de investigação e estes podem ser imprescindíveis para realizamos a leitura densa do local. Segundo Geertz (2008, p. 7) esta imersão busca fazer uma "descrição densa”, já que “[ [...] fazer a etnografia é como tentar ler (no sentido de "construir uma leitura de") um manuscrito estranho, desbotado, cheio de elipses, incoerências, emendas suspeitas e comentários tendenciosos".

Adicionalmente, no que tange às entrevistas, consideramos que o discurso do outro é sempre permeado por outras vozes e o que realmente importa não é a configuração formal do discurso, mas o próprio discurso em si, carregado de emoções e vivências.

Na realidade, o locutor serve-se da língua para suas necessidades enunciativas concretas (para o locutor, a construção da língua está orientada no sentido da enunciação da fala). Trata-se, para ele, de utilizar as formas normativas (admitamos, por enquanto, a legitimidade destas) num dado contexto concreto. Para ele, o centro de gravidade da língua não reside na conformidade à norma da forma utilizada, mas na nova significação que essa forma adquire no contexto. O que importa não é o aspecto da forma linguística que, em qualquer caso em que esta é utilizada, permanece sempre idêntico. Não; para o locutor o que importa é aquilo que permite que a forma linguística figure num dado contexto, aquilo que a torna um signo adequado às condições de uma situação concreta dada (BAKHTIN, 2006, p. 83). 
Revista Educação e Políticas em Debate - v. 7, n. 1, p. 95 - 112 - jan./abr. 2018 - ISSN 2238-8346

Acreditamos que estas técnicas para levantamento do material empírico são aderentes ao estudo proposto, uma vez que os elementos citados podem contribuir tanto para a compreensão da realidade do campo quanto para o entendimento dos discursos emergidos na interação dos pesquisadores com os sujeitos do campo.

\title{
Apresentando os discursos dos sujeitos do campo
}

Assim, delimitado o contex to e os objetivos deste trabalho, selecionamos trechos das falas dos entrevistados e também de descrições relativas às observações in loco buscando compreender as concepções e os saberes dos participantes e os significados que lhes são atribuídos.

Notamos que é muito forte o fazer-se sujeito em meio às lutas não apenas pela terra, mas pela dignidade enquanto ser humano. As lutas, nessa perspectiva, são um processo educativo para quem as vivencia:

\begin{abstract}
[…] tô começando, né, a graduação agora. E formação política a gente adquire na luta mesmo, sabe, nos movimentos sociais e essas coisas assim. Desde quando tinha os meus dez anos de idade, sabe, comecei muito cedo na militância e na luta pelos direitos das crianças, adolescentes, na luta pela terra, na luta pela moradia e agora pela educação no campo, pela educação pública de qualidade, já que a gente vem sofrendo alguns retrocessos que não vêm de agora e a educação é uma constante, a gente sempre tem que tá querendo mais a educação realmente de qualidade, pública (João).
\end{abstract}

Sobre o processo educativo no campo, João faz uma crítica dizendo que muitas vezes a educação que é gerida no campo se assemelha à Educação no campo (e não a Educação do Campo), ou seja, que foi simplesmente deslocada da cidade para o campo, sem se ater às especificidades deste contexto. O próprio sujeito, que foi educado no campo, não tinha consciência sobre esse processo, passou a tê-lo quando iniciou seus estudos na Licenciatura:

aí depois quando eu fui conhecendo mesmo e descobrindo o que é educação no campo, apesar de morar no campo eu não sabia, né, porque não é porque a gente mora no campo que sabe o que é Educação no campo e não é isso que a sociedade quer, eles trazem não uma educação do campo, eles trazem uma educação no campo que é aquela educação que é tirada das cidades e simplesmente colocada no campo. Então, aí depois que eu fui conhecer o curso […] (João). 
A fala de João pode ser relacionada às palavras de Otávio, que chama a atenção para o processo educativo que não é neutro, já que cada comunidade pensa e estrutura a educação a partir do seu próprio contexto:

a educação não é neutra, a educação, ela parte do projeto de cada sociedade e na perspectiva das classes sociais. Então as classes dominantes vivem querendo destruir a Educação do Campo; nossa escola local vive ameaçada de fechamento, o prefeito pretende fazer um centro educacional na cidade, que vai levar todos os alunos para lá, com recursos e tal. [...] os recursos são importantes, mas são também importantes no campo. Com essa proposta de deslocar todos os alunos para um centro educacional na cidade, ele vai deslocar toda uma perspectiva de educação própria do campo. $O$ aluno, ele vai perder esse convívio e essa possibilidade de aplicação na prática daquilo que se aprende na escola (Otávio).

Além disso, nota-se na fala do entrevistado uma crítica que corrobora com o histórico levantado na parte teórica deste artigo: na maioria das vezes o poder público não se interessa pelo processo educativo no ambiente do campo, e este acaba sendo deixado às margens. Assim, a consciência do morador da comunidade e o seu sentimento de pertença é importante na visão de João, o que faz com que a escola seja mantida, caso contrário entraria em um processo contínuo de desestruturação:

[...] a prefeitura não dá muito incentivo, mas tem pais que resistem, fala assim: "não, meu filho vai estudar aqui [na escola do campo]". Por causa desses que a escola ainda continua funcionando. Mas aqueles que não têm muito compromisso com a escola e que não vê a importância de uma escola próximo de sua casa manda pra cidade, a prefeitura busca, então [...]. Porque quando o pai não quer, ele não vai mandar [para a escola da cidade], ele já tem uma certa consciência. Eu vejo que é importante a escola aqui dentro, então vou mandar meu filho pra escola [do campo], ai a prefeitura leva pra escola [do campo]. Mas é cômodo porque se o pai não quer, a prefeitura também não quer. Aí... mand̆a tudo pra cidade (João).

O entrevistado deixa bastante claro que a Educação do Campo deve valorizar o próprio homem do campo, seus saberes e suas experiências, em sua fala “valorizar as raízes”, o que também já havia sido demarcado na fala de Otávio:

eu vou sair da minha raiz pra virar um doutor... por que eu não posso ser um agricultor? Por que eu não posso ser um professor daquela escola? Então é valorizar isso, sabe. Acho que a educação do campo, uma escola ideal é essa, sabe, seja uma construção a partir daquilo ali, daquela comunidade, dos ensinamentos que a comunidade tem também, sabe? Valorizar a comunidade, valorizar o homem do campo, as raízes daquilo ali e que não tire aquele aluno e fale pra ele: "você tem que estudar pra ir pra cidade e ser um doutor" (João). 
Buscamos conhecer a estrutura física da comunidade e, então, questionamos João sobre as características do local. $\mathrm{O}$ entrevistado nos informou que atualmente na comunidade residem aproximadamente 115 famílias que vivem de atividades agrícolas e pastoris, como a criação de gado leiteiro e o plantio de hortaliças. No entanto, João deixou evidente que a monocultura da cana-de-açúcar também chegou à comunidade e atualmente é a principal atividade econômica: os assentados arrendam a terra para uma usina e outros princípios, como a agricultura familiar, por exemplo, ficam em um segundo plano.

João também relaciona a monocultura da cana-de-açúcar com as questões educacionais e o sentimento de pertença à comunidade, visto que sob sua ótica o arrendamento de terras simplesmente transforma em grande latifúndio os pequenos minifúndios produtores e o homem do campo não se apropria diretamente da terra, mas apenas do dinheiro gerado por esta.

[...] uma coisa que influencia inclusive na educação é a questão da monocultura, sabe? Porque a monocultura é a contramão da agricultura familiar e infelizmente lá isso é normal sabe [...]. Você vai falar sobre a permanência do jovem ali na comunidade, como você vai trabalhar isso sendo que o pai dele só arrenda, a renda da família vem da cana? (João).

Além da questão do arrendamento das terras, João também mostra que cada vez mais a escola do campo vem se distanciando do seu contexto, inclusive com a falta de atividades e propostas pedagógicas que busquem uma relação entre a escola e o seu meio, e cita uma experiência de Escola Familiar Agrícola (EFA) que tinha tal perspectiva e funcionou durante certo tempo no assentamento, mas foi fechada por falta de recursos:

[...] eu vejo que como não é uma construção coletiva, né, da comunidade com os professores ali... alguma coisa quando afeta diretamente a escola aí eles procuram, mas, assim, de modo geral, não muito. [...] já teve [projetos pedagógicos], inclusive lá teve um ano que funcionou uma escola agrícola, mas, assim, tinha essa escola, a escola lá do Ensino Fundamental, básico, aí se criou uma outra escola que foi um movimento muito forte que o pessoal fez de se formar uma escola familiar agrícola lá, só que não foi por muito tempo, acho que ficou por tempo lá e acabou, provavelmente por falta de recursos (João).

O professor Otávio também abordou a experiência da EFA e a pedagogia da alternância: 
Agrícola tem esse nome porque ela envolve toda a família, não é só o aluno, o aluno não é descontextualizado da família e cada aluno da $\mathrm{EFA}$, necessariamente, tem que desenvolver um projeto de produção, independente de ser aluno do fundamental ou médio. [...] então aí ele já vai começar a relacionar aquilo que ele aprende, a Matemática, a Biologia, como cuidar, como alimentar o animal [...]; então é a educação que é casada com a experiência da necessidade de sobrevivência no campo (Otávio).

Segundo os entrevistados, a instituição responsável pela escolarização dos sujeitos do campo é regida pela prefeitura da cidade próxima, apesar de ter sido construída, em grande parte, pelos assentados da comunidade. Assim sendo, mantém as especificidades da cidade e não do campo. Além disso, oferta apenas o primeiro segmento do Ensino Fundamental $\left(1^{\circ}\right.$ ao $5^{\circ}$ ano) no turno matutino. Os alunos que já concluíram esta etapa são direcionados à instituição de ensino localizada na cidade.

Partindo das falas de João e Otávio, percebemos que a escola do campo sofre um processo histórico de exclusão, já que ambos relataram que diversas vezes a escola da comunidade quase foi fechada pela prefeitura local: apenas não o foi por um movimento de luta dos próprios integrantes da comunidade, que viam no processo educativo uma forma de reconhecimento e pertencimento dos alunos aos princípios do local.

Além disso, demarcam claramente em suas falas a importância de uma educação legítima do campo, pois a chamada "educação da cidade” possui outros princípios e, como afirma Otávio, é "[...] uma educação que serve para montar a mão de obra reserva que o mercado precisa”.

Assim, a Educação do Campo pode ser entendida como um modelo contra-hegemônico e que, de acordo com João, “[ [...] vai além do que uma escola com professores dando aula ... vai além do que a Educação tradicional vem nos trazer". É um processo educativo que vê o homem em sua plenitude, dentro do seu contexto, e os conceitos científicos naturalmente surgem na tentativa de solucionar os problemas reais, de situações reais, de pessoas reais.

É nessa perspectiva que defendemos que as práticas pedagógicas devem ser elaboradas a partir da realidade dos alunos, como ressalta Freire (1994). É importante que os sujeitos do campo se reconheçam no processo educativo e consequentemente tenham seus saberes e experiências reconhecidos. Os conteúdos trabalhados devem partir da realidade do campo, o que não quer dizer que tais conhecimentos não possam ser aprofundados. Ir além é um direito dos estudantes e um dever do docente. Partindo disso, e considerando as ideias e saberes dos participantes apresentamos, nas seções seguintes, encaminhamentos para uma proposta didática intercultural voltada ao ensino de Ciências e de Matemática. 
Revista Educação e Políticas em Debate - v. 7, n. 1, p. 95 - 112 - jan./abr. 2018 - ISSN 2238-8346

\section{Educação do Campo e a controvérsia do modelo agroecológico: uma proposta didática}

O modelo agroecológico, segundo Lima e Carmo (2006, p.66), "permite melhorar substancialmente o manejo dos recursos naturais, a qualidade nutricional dos alimentos e o resultado econômico das comunidades rurais", contribuindo tanto para o desenvolvimento de uma agricultura ecológica quanto para a biodiversidade.

Assis (2005, p. 175) aponta que a agroecologia surge como um movimento alternativo à modernização agrícola que serve unicamente aos interesses da produtividade agrícola como fator de medição de eficiência:

a modernização da agricultura privilegiou somente o aumento da produtividade agrícola como parâmetro para avaliar sua eficiência, desconsiderando o agricultor e o ambiente como partes do mesmo processo de desenvolvimento, gerando diversos problemas sociais e ambientais. Como contraponto, surgiram movimentos de agricultura alternativos ao modelo de produção atualmente predominante, baseados em princípios agroecológicos e caracterizados por diferentes correntes de pensamento.

A agroecologia surge, então, como um paradigma emergente em substituição à agricultura industrial/convencional e tem como principais marcos epistemológicos o holismo e a abordagem interdisciplinar com ênfase no modelo socioambiental, enquanto o modelo anterior tem como marcos o positivismo, o reducionismo e a ênfase no mercado (JESUS, 2005). Jesus (2005, p. 41), parafraseando Carrol e colaboradores $(1990)^{5}$, "apresenta a agroecologia como ciência emergente com base em quatro ciências: a agricultura, a ecologia, a antropologia e a sociologia rural".

$\mathrm{Na}$ visão de Assis (2005), a agroecologia pode ser entendida como um movimento alternativo ao modelo de produção tradicional. O modelo agroecológico utiliza tecnologias que respeitam o meio ambiente e que alteram pouco ou minimamente as condições de equilíbrio entre os organismos participantes - o homem é visto como parte integrante da natureza (“trabalhar com ela”) e não apartado dela ("trabalhar nela”).

O modelo agroecológico tem sido incorporado por diversos movimentos sociais como parte de sua estratégia político-social, apontam Silva e Miranda (2015). Além disso, a agroecologia aparece como eixo norteador não só na Licenciatura em Educação do Campo,

${ }^{5}$ CARROL, C. R.; VANDERMEER, J. H.; ROSSET, P. M. Agroecology. New York: McGrawHill, 1990. 
mas também na formação de outros profissionais oriundos de cursos diversos (PINTO et al., 2016).

De acordo com Assis (2005, p. 180), a Agricultura Familiar pode ser entendida à luz do modelo agroecológico:

[...] os limites teóricos da agroecologia se adaptam mais facilmente à realidade da agricultura familiar [...]. Essa opção pela produção familiar se embasa ainda no fato de que a utilização de modelos agroecológicos de produção apresenta-se como importante instrumento para o desenvolvimento de agricultores familiares, especialmente os de menor nível de capitalização.

Podemos perceber, então, que os princípios da Agroecologia e da Agricultura Familiar perpassam a Educação do Campo, já que tal perspectiva educativa busca novas relações entre os homens e a natureza e levam em consideração a sustentabilidade ambiental, agrícola, agrária, econômica e social (BRASIL, 2007). Além disso, a Educação do Campo busca desenvolver práticas educativas em oposição aos modelos tradicionais de produção de conhecimento e de ciência que estruturaram a moderna produção capitalista na agricultura (CALDART, 2008).

\section{Uma alternativa pedagógica: a horta agroecológica e o ensino de Ciências e de Matemática}

Como o intuito de promover um diálogo intercultural entre os saberes do campo e os saberes científicos, sugerimos uma proposta pedagógica apoiada nos princípios da agroecologia, que prevê o homem em relação holística com a terra e os sistemas de produção. Propomos a construção de uma horta agroecológica como campo laboral, implantada no espaço escolar.

Neste local, os estudantes podem revelar seus saberes, e para além, têm a oportunidade de realizar pesquisas subsidiando discussões sobre diversos métodos (trabalho, cultivo, escoamento, consumo, renda, dentre outros), que podem contribuir para o fortalecimento de suas atividades no campo, visto que um problema levantado pelos assentados foi a forte influência da monocultura da cana-de-açúcar, a falta de investimentos e a dificuldade de escoamento desta produção.

Esta proposta pode contemplar todos os anos de escolarização, assim como pode ser trabalhada por todas as áreas do conhecimento, inclusive interdisciplinarmente. Contudo, 
optamos por discutir ideias relacionadas ao Ensino Fundamental, mais especificamente ao ensino de Ciências e de Matemática. Mediante esta proposta os alunos podem ter a oportunidade de desenvolver atividades práticas e reais, relacionadas ao seu cotidiano que culminem em discussões e reflexões, as quais podem ser ampliadas para o campo das ciências, promovendo a alfabetização científica.

A horta agroecológica se difere das hortas tracionais. Não há uma linearidade no cultivo, tampouco na produção. Os diversos tipos de culturas desenvolvidas nesse espaço não o são separadamente, mas sim uma ao lado da outra, obedecendo a uma rotatividade. Entretanto, para a sua construção, é indispensável o estudo sobre plantas companheiras (uma planta que protege a outra). Um exemplo de plantas companheiras são a beterraba e a alface, o consórcio entre estas duas espécies beneficia ambas as culturas, pois o inseto que ataca a beterraba não ataca a alface, fato que diminui o ataque de pragas. Além disso, estas espécies juntas aproveitam melhor os nutrientes do solo. Outra característica observada se refere à diversidade e à rotatividade da horta agroecológica que possibilitam o cultivo de diversos tipos de produtos, fato que contribui para o escoamento da produção, uma vez que certos alimentos se desenvolvem melhor em determinadas épocas do ano.

A horta agroecológica como campo laboral pode originar um ensino/aprendizado rico e significativo, pois pode proporcionar experiências que impulsionem a transformação dos sujeitos de modo que estes possam, de maneira real, identificar pistas e possibilidades para construir e (re)construir, significar e (re)significar os saberes da comunidade e os saberes científicos. Assim, considerando o ensino de Ciências e de Matemática, a horta pode ser utilizada tanto para problematizar as práticas agrícolas instauradas quanto para promover discussões, reflexões e articulações entre os saberes do campo e os saberes científicos, como forma de dinamizar o currículo da escola do campo, em uma perspectiva intercultural (SASSI, 2014).

Devemos ressaltar que a construção da horta agroecológica é uma proposta pedagógica desenvolvida em longo prazo, que envolve a ação do professor, dos estudantes e da comunidade. Estes, em acordo, devem participar dos diversos estágios: escolha do local, das hortaliças, das plantas medicinais e condimentares, da seleção das ferramentas e das tecnologias para sua implementação. Além disso, precisam realizar um estudo prévio sobre a terra, o plantio, e sobre os saberes da comunidade para o desenvolvimento de um projeto desta natureza. 
Assim, este trabalho apresenta várias possibilidades de aprendizado nas diversas áreas do conhecimento, no entanto, apresentaremos apenas apontamentos, de forma bem sucinta, que podem ser trabalhados no ensino de Ciências e de Matemática.

Conhecimentos sobre Ciências - por meio dos alimentos produzidos na horta, é possível discutir sobre a água, a chuva, o clima, o solo, o desenvolvimento das plantas, as plantas companheiras, vitaminas e minerais, agrotóxicos e adubos (produzidos pelos sujeitos do campo e os produzidos industrialmente), controle de pragas, alimentação saudável, nutrição, dentre outros. Ademais, é possível refletir como os raios do Sol podem influenciar a disposição das mudas e influenciar em seu formato.

Conhecimentos Matemáticos - podem ser trabalhados desde estudos de localização até a construção das ferramentas utilizadas pelos assentados para o manejo da terra. Exemplos incluem o espaço disponível, localização no lote, formato da horta, área e perímetro da região plantada, seleção e contagem das sementes, cultivo das mudas em placas, quantidade de adubos, agrotóxicos e água, desenvolvimento e crescimentos das hortaliças que podem ser relacionados também às fases da lua, preço de mercado dos produtos, preço de venda, lucro, dentre outros.

Diante deste contexto, percebemos a existência de um campo fértil para a elaboração de atividades pedagógicas que podem emergir a partir das vivências e dos conhecimentos dos estudantes e dos moradores da comunidade. Em uma sequência didática de aproximadamente oito aulas, a qual se pretenda trabalhar e discutir questões referentes a adubos e agrotóxicos, por exemplo, o professor pode proceder da seguinte forma:

Primeiro momento - o docente pode promover uma visita às hortas familiares da região, realizando um trabalho de levantamento, no qual os alunos terão que mapear quais os tipos de adubos e agrotóxicos são utilizados pelos pequenos produtores, registrando suas observações em um diário de campo.

Segundo momento (pode acontecer no campo ou em sala de aula) - realizado o levantamento, os professores podem problematizar as situações com perguntas: quais os adubos e agrotóxicos que vocês encontraram? Qual a diferença entre eles? Quais são produzidos pela comunidade? Podemos dizer que algum deles é melhor do que o outro? Por quê? Para vocês, qual a diferença entre eles? Qual é mais saudável? Será que existem outras formas de proteger as hortaliças das pragas? Vocês notaram alguma diferença entre as plantas produzidas com agrotóxicos e as produzidas com insumos produzidos no campo? 
Terceiro momento - Levar os alunos à sala de informática para que eles pesquisem quais são as doenças humanas causadas pelos agrotóxicos e se existem métodos menos agressivos à saúde e à plantação que podem ser utilizados no campo.

Quarto momento - pedir aos alunos para que sistematizem o que foi discutido e organizem uma exposição para apresentar à comunidade, momento no qual também apresentarão seus benefícios e impactos, tanto para a produção quanto para o consumo destes alimentos. Além disso, poderão apresentar propostas alternativas para o avanço do trabalho no campo.

Cabe ressaltar que este trabalho se configura como oportunidade para desenvolver propostas interdisciplinares. A elaboração e o desenvolvimento da horta agroecológica perpassa o currículo da Educação do Campo, pois não fica restrito apenas a uma disciplina, mas transita por todas. Dessa forma, a horta pode-se relacionar com a matemática (perímetro, área, grandezas e proporções), geografia e ciências (estudos sobre a terra, monocultura, latifúndio, rochas, composição química, adubos, pesticidas) e história (a própria história de lutas da comunidade e da escola, a questão da reforma agrária).

Os temas curriculares precisam ser negociados pela própria comunidade escolar dialogando os saberes da ciência formal com os saberes próprios da comunidade e utilizandoos na resolução de problemas do cotidiano. De acordo com Sassi (2014), a horta agroecológica dialoga diretamente com o contexto da Educação do Campo, já que está diretamente voltada aos interesses da vida no campo. A autora (2014, p. 54) ressalta que, além disso, busca "utilizar dos conhecimentos advindos da comunidade, da realidade das famílias, da atividade de renda dos agricultores para discutir, elaborar e aprender a partir da junção contex tualizada na forma de currículo escolar tematizado”.

Por fim esta proposta evidencia, ainda, a interculturalidade dos saberes: aqueles advindos das ciências "hegemônicas" e já consolidadas historicamente e os saberes próprios da comunidade, ambos imbricados no desenvolvimento da horta agroecológica. Trata-se de uma alternativa que parte da realidade dos educandos, propicia discussões e reflexões para a construção de novos conhecimentos, estimula a criatividade, contribui para valorização dos saberes do campo e não só dos saberes hegemônicos, bem como favorece o avanço das atividades exercidas pelas famílias que vivem no campo. 


\section{Considerações Finais}

A Educação do Campo atravessou e ainda atravessa momentos difíceis na sua luta por consolidação: embora exista nas leis, na prática o que se vê é bastante diferente. As entrevistas possibilitaram recontar a história dos sujeitos a partir de sua própria voz e desta forma também quebrar determinados estereótipos e pré-noções acerca da realidade e dos moradores. Além disso, a partir da fala dos sujeitos, percebe-se a importância de uma Educação do Campo que seja realmente do campo, ou seja, voltada aos interesses dos sujeitos daquela realidade e que pela escola perpasse o sentimento de pertença à terra e à comunidade.

Os educandos do campo possuem saberes específicos, advindos de uma cultura de pertença própria e que devem ser respeitados e valorizados. Estes estudantes, na sua vida diária, vivenciam experiências sociais de aprendizado na esfera informal, os quais rompem os muros da escola. Assim, é importante que eles possam, por meio da educação, aprofundar e construir conhecimentos, de modo que estes possam ser utilizados na sua busca por uma vida mais justa e igualitária.

A imposição de uma cultura hegemônica pouco há de contribuir para o desenvolvimento humano e profissional das comunidades do campo, ao contrário, só faz aumentar a desigualdade e a exclusão. Especificamente em Ciências e em Matemática, a educação distante desta realidade só tem a reforçar o desenvolvimento de atividades pautadas no conhecimento técnico e racional, na memorização e na reprodução, o que por vezes torna a prática pedagógica obsoleta e sem sentido.

Neste território de desigualdade social e exclusão, a Educação do Campo tem sido uma problemática. Os avanços desta modalidade de ensino, no Brasil, ainda são insuficientes. Há muito por se cultivar para a promoção de uma Educação do Campo, desenvolvida com as pessoas do campo. Precisamos urgentemente de inciativas que se concretizem em políticas públicas, ações e práticas educacionais para que reverta este quadro de complexidade em favor dos sujeitos a quem esta educação é de direito.

Além disso, é necessário que pesquisas tragam à tona as vozes destes sujeitos que, de alguma forma, encontram-se silenciados nos debates educacionais. Abordem os conhecimentos e a cultura desses povos, promovendo a valorização de seus conhecimentos tanto pela sociedade quanto pelas instituições de formação de professores. Produzam com estas pessoas do campo subsídios pedagógicos e materiais didáticos que privilegiem os conhecimentos oriundos do campo, bem como o seu aprofundamento. 
Nesta perspectiva, a horta agroecológica é apenas um indicativo de trabalho para ser desenvolvido na escola, pautado nos interesses da própria comunidade e que busca o diálogo entre os saberes da ciência com os saberes tradicionais do campo. A agroecologia é o sustentáculo do projeto, que tem como principal característica o respeito à terra e à natureza. Com o seu desenvolvimento, buscamos não apenas a alfabetização científica e matemática dos alunos, mas também o seu senso crítico e reflexivo perante à sua condição de vida.

\section{Referências}

ASSIS, R. L. (2005). Agroecologia: visão histórica e perspectivas no Brasil. In: AQUINO, A. M.; ASSIS, R. L (Orgs.). Agroecologia: princípios e técnicas para uma agricultura orgânica sustentável. Brasília: Embrapa Informação Tecnológica. p.173-184.

BAKHTIN, M. Marxismo e filosofia da linguagem. São Paulo: Editora Hucitec, 2006.

BOGDAN, R.; BIKLEN, S. Investigação qualitativa em educação. Portugal: Porto Editora, 1994.

BRASIL. Lei n. 9.394, de 20 de dezembro de 1996. Estabelece as Diretrizes e Bases da Educação Nacional. Disponível em: <http://www.planalto.gov.br/ccivil_03/leis/19394.htm> Acesso em: 02 ago. 2016.

Educação do Campo: diferenças mudando paradigmas. Brasília: Secretaria de Educação Continuada, Alfabetização e Diversidade (Secadi/MEC), 2007.

CALDART, R. S. Sobre educação do campo. In: SANTOS, C. A. (Org.). Por uma educação do campo: campo-políticas públicas-educação. Brasília: INCRA/MDA, 2008. p. 67-86.

Por uma educação do campo: traços de uma identidade em construção. In: Por uma educação do campo: identidade e políticas públicas. Caderno 4. Brasília: Articulação Nacional Por Uma Educação do Campo, 2002, p. 25-36.

Educação Do Campo: notas para uma análise de percurso. Trabalho, Educação e Saúde, Rio de Janeiro, v.7, n.1, p.35-64, mar./jun. 2009.

FREIRE, P. Educação como Prática da Liberdade. São Paulo: Editora Paz e Terra, 1967.

Conscientização: teoria e prática da libertação uma introdução ao pensamento de Paulo Freire. São Paulo: Editora Cortez \& Moraes, 1979.

Pedagogia do Oprimido. 11. ed. São Paulo: Editora Paz e Terra, 1994.

GEERTZ, C. A interpretação das culturas. Rio de Janeiro: Editora LTC, 2008.

JESUS, E. L. Diferentes abordagens de Agricultura Não-Convencional: História e Filosofia. In: AQUINO, A. M.; ASSIS, R. L. (Orgs.). Agroecologia: princípios e técnicas para uma agricultura orgânica sustentável. Brasília Embrapa Informação Tecnológica, 2005. p.2 1-48. 
LIMA, A. J. P.; CARMO, M. S. Agricultura Sustentável e a Conversão Agroecológica. Revista Desenvolvimento em Questão, Unijui, v.4, n.7, p. 47-72, jan./jun. 2006.

MARCONI, M. A.; LAKATOS, E. M. Técnicas de Pesquisa. São Paulo: Editora Atlas, 2010.

MUNARIM, A. Elementos para uma educação no Campo. In: MOLINA, M. C.(Org.).Educação do Campo e pesquisa: questões para reflexão. Brasília: Ministério do Desenvolvimento Agrário, 2006. p. 5-26.

NASCIMENTO, C. G. Educação do Campo e Políticas Públicas para Além do Capital: hegemonias em disputas.2009. 301 f. Tese (doutorado em educação). Universidade de Brasília, Brasília: 2009.

PINTO, S. D, et al. A formação de professores para a agroecologia e a experiência do curso de Licenciatura em Educação do campo da UFRRJ. Cadernos de Agroecologia, Recife, v.1 1, n.01, [s/p], jun. 2016.

ROCHA, A. L. C., ECKERT, C. Etnografia: saberes e práticas. Revista Iluminuras, [s/d], v. 9, n. $21,[\mathrm{~s} / \mathrm{p}], 2008$.

SASSI, J. S. Educação do campo e ensino de ciências: a horta escolar interligando saberes. 2014. 159 f. Dissertação (Mestrado em Educação). Universidade Federal do Rio Grande, Rio Grande: 2014.

SILVA, L. H., MIRANDA, É. L. Educação do campo e agroecologia: diálogos em construção. In: Reunião Nacional da ANPED, 37, 2015, Florianópolis, Anais... Florianópolis: [s/n], 2015.

TRIVIÑOS, A. S. Introdução à Pesquisa em Ciências Naturais: a pesquisa quantitativa na Educação. São Paulo: Atlas, 1987. 